Muzeum Archeologiczne

i Etnograficzne w Łodzi

Piotr Papiernik, Dominik K. Płaza

\title{
ZAGOSPODAROWANIE PRZESTRZENI W ŚRODKOWEJ \\ I MŁODSZEJ EPOCE KAMIENIA NA STANOWISKU REDECZ KRUKOWY 20, GM. BRZEŚĆ KUJAWSKI, WOJ. KUJAWSKO-PO- MORSKIE, W ŚWIETLE METODY SKŁADANEK
}

Zarys treści. Na stanowisku 20 w Redczu Krukowym odkryto około 25 tysięcy przedmiotów krzemiennych. Składanki tych materiałów pozwalają analizować m.in. zagospodarowanie przestrzenne w różnych okresach epoki kamienia.

Slowa kluczowe: Redecz Krukowy, epoka kamienia, krzemień „czekoladowy”, metoda składanki.

\section{WPROWADZENIE}

Stanowisko 20 w miejscowości Redecz Krukowy położone jest we wschodniej części Kujaw, na pograniczu gmin Brześć Kujawski i Osięciny, w strefie wysoczyzny morenowej, na niewielkim płacie gleb bielicowych wykształconych na podłożu piaszczystym (ryc. 1); jest to rejon intensywnych badań wykopaliskowych prowadzonych przez Muzeum Archeologiczne i Etnograficzne w Łodzi (Grygiel 2004; 2008; Papiernik 2012). W niewielkiej odległości od stanowiska znajduje się niecka zatorfionego jeziora Czajno oraz kilkanaście innych mniejszych zbiorników wodnych o genezie polodowcowej, które funkcjonowały od końca plejstocenu aż po okres subborealny (Nalepka 2005; 2008; Nowaczyk 2008).

Badania na stanowisku trwały od sierpnia 2006 roku do października 2010 roku, przez pięć sezonów badawczych, w sumie 14 miesięcy. W tym czasie rozpoznano powierzchnię $7487 \mathrm{~m}^{2}$ (Papiernik 2012, s. 193, ryc. 3), na której okryto bardzo dużą liczbę źródeł archeologicznych, w tym 140 tys. fragmentów naczyń ceramicznych oraz 25 tys. wyrobów krzemiennych, o bardzo zróżnicowanej chronologii i funkcji. Badaniami, z ramienia Mu- 


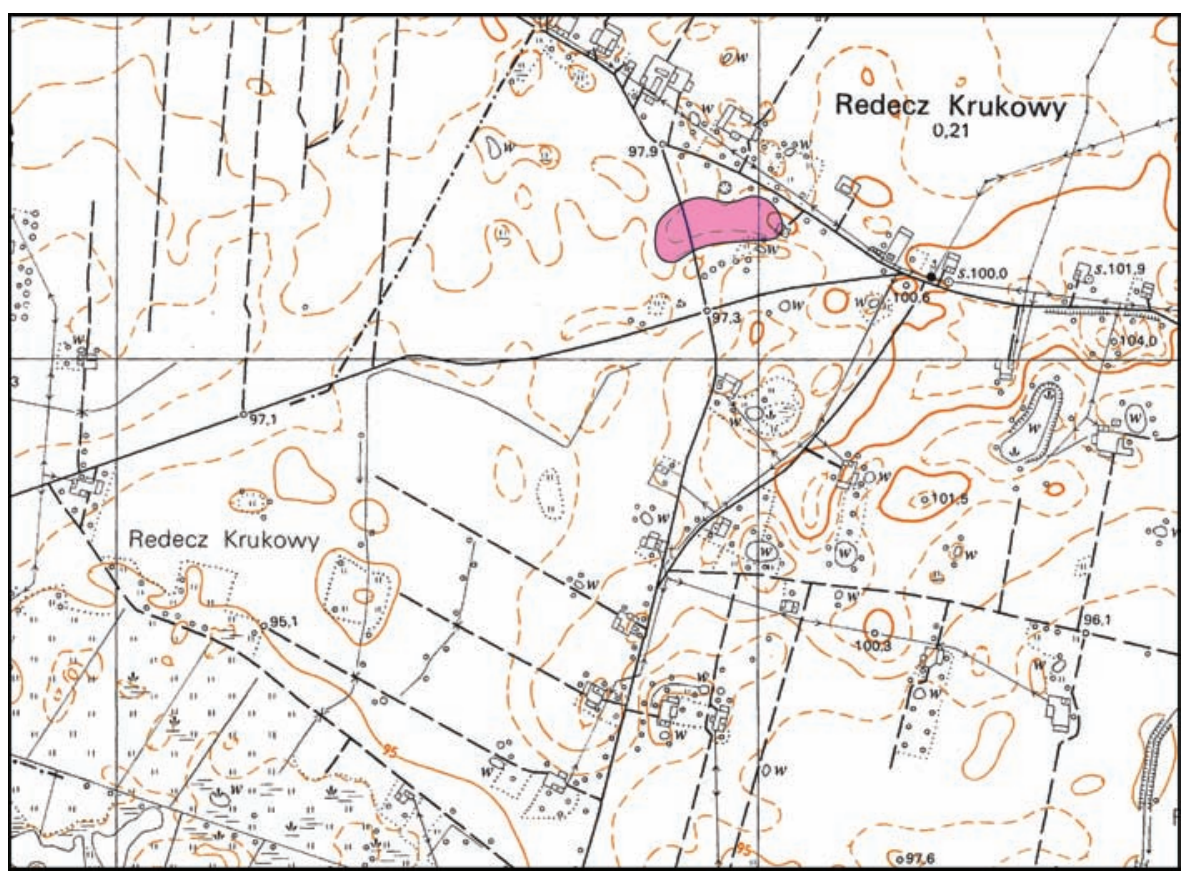

Ryc. 1. Redecz Krukowy, gm. Brześć Kujawski, stanowisko 20. Lokalizacja stanowiska na mapie w skali 1:10 000 (rys. P. Papiernik)

Fig. 1. Redecz Krukowy, Brześć Kujawski commune, site 20. Location on the map at a scale of 1:10 000 (drawn P. Papiernik)

zeum Archeologicznego i Etnograficznego w Łodzi, kierował dr Piotr Papiernik przy współpracy mgr Dominika Płazy. Prace terenowe finansowała Fundacja Badań Archeologicznych Imienia Profesora Konrada Jażdżewskiego przy udziale Muzeum Archeologicznego i Etnograficznego w Łodzi.

\section{WYBRANE ELEMENTY METODY BADAŃ TERENOWYCH}

Prace wykopaliskowe prowadzone były wyłącznie ręcznie przy użyciu łopat i drobnego sprzętu eksploracyjnego. Cały wydobyty osad systematycznie przesiewano, stosując sita ręczne z siatką otworów o wymiarze $4 \times 4 \mathrm{~mm}$. Po zdjęciu i przesianiu warstwy ornej eksplorowano cienkie warstwy, których kilka (najczęściej 5-8) dokumentowano łącznie, jako poszczególne warstwy mechaniczne o miąższości $10 \mathrm{~cm}$. W czasie tych prac stosowano tzw. planigrafię z numeracją artefaktów, a materiały źródłowe uzyskane z przesiewania inwentaryzowano w polach o wymiarach $5 \times 5 \mathrm{~m}$ lub w obiektach. Dzięki 
zastosowaniu sit uzyskano blisko 100\% źródeł ruchomych, niezależnie od głębokości ich zalegania. Zaskakująco dużo materiału przyniosło przesianie warstwy ornej. $\mathrm{Z}$ eksploracji współczesnego humusu pozyskano liczne inwentarze krzemienne, również związane z mezolitem. Wiedza o rzeczywistej ilości, strukturze i chronologii materiałów w poszczególnych częściach wykopu miała zasadnicze znaczenie w trakcie procedury składania i interpretacji inwentarza krzemiennego. Obserwacje te okazały się szczególnie istotne dla analizy stratygrafii i stopnia zachowania poszczególnych części stanowiska, a także kwestii związanych ze strategią produkcji i wykorzystywania krzemieni oraz funkcjonalnego zagospodarowania przestrzeni obozowisk lub osad w poszczególnych poziomach chronologicznych (Schild 1980).

\section{OGÓLNA CHARAKTERYSTYKA FAZ ZASIEDLENIA STANOWISKA}

Wstępne wyniki prac wykopaliskowych przeprowadzonych na stanowisku były już prezentowane (Papiernik 2012), dlatego ich charakterystyka zostanie ograniczona przede wszystkim do krótkiego omówienia tych faz osadniczych, z którymi związane były materiały krzemienne. Uwzględniono przy tym nowe dane wynikające z postępu prac zmierzających do pełnego opracowania źródeł, w tym z ciągle zwiększającej się ilości oznaczeń radiowęglowych. Obecnie dysponujemy już 41 datami ${ }^{14} \mathrm{C}$, w tym 19 wykonanymi metodą akceleratorową w Poznańskim Laboratorium Radiowęglowym Fundacji Uniwersytetu im. Adama Mickiewicza w Poznaniu oraz 22 metodą ciekłych scentylatorów w Pracowni Radiochemicznej Muzeum Archeologicznego i Etnograficznego w Łodzi.

Najstarszym elementem kulturowym na stanowisku są pozostałości osadnictwa mezolitycznego ze środkowej epoki kamienia. Na obecnym etapie badań z mezolitem można łączyć inwentarze krzemienne liczące łącznie prawie 7 tysięcy okazów, które tworzą kilkanaście izolowanych koncentracji materiału. Wstępna analiza chronologiczna form charakterystycznych, takich jak rdzenie, narzędzia, a przede wszystkim zbrojniki wskazuje, że reprezentują one różne tradycje kulturowe środkowej epoki kamienia. Do form stosunkowo wczesnych związanych z kulturą Duvensee/Komornica lub Maglemose należy zaliczyć półtylczaki z surowca odłupkowego i wiórowego, jednozadziorce, ciosak, oraz na przykład liściak maglemoski (Płaza 2015). Dość wczesne są także smukłe formy trójkątne oraz wiórki retuszowane, na przykład zbrojniki typu Nowy Młyn, związane z okresem borealnym, z grupą Sværdborg (Kozłowski 1989; Bagniewski 1996; Sørensen 2006; Płaza 
2015). Jako późnomezolityczne można traktować formy geometryczne wiórkowe i wiórowe, takie jak trapezy, prostokąty, trójkąty oraz zbrojniki typu Wieliszew, związane z kulturą janisławicką (Kozłowski, Kozłowski 1977; Wąs 1999; 2005). Większość krzemieni pochodzących z mezolitu wykonana została z surowca narzutowego. Na obecnym etapie badań z mezolitem należy łączyć cztery oznaczenia ${ }^{14} \mathrm{C}$, które potwierdzają obecność osadnictwa w VIII i VII tys. BC (Papiernik 2012).

Wśród odkrytych źródeł rozpoznano również materiały kultur cyklu wstęgowego; ich szczególnie bogate osadnictwo znane jest właśnie z tego rejonu Kujaw (Grygiel 2004; 2008; Pyzel 2010). W zachodniej części wykopu zarejestrowano niewielkie skupienie około 20 ułamków naczyń kultury ceramiki wstęgowej rytej, w środkowej zaś natrafiono na 25 fragmentów pochodzących z dwóch naczyń kultury ceramiki wstęgowej kłutej. Z tym osadnictwem można również łączyć niewielki zbiór typowych przedmiotów krzemiennych: rdzeń wiórowy jednopiętowy, dwa półtylczaki i jedno narzędzie kombinowane składające się z półtylczaka z drapaczem, z typowym wyświeceniem półtylców. Niemal wszystkie okazy zostały wykonane z krzemienia bałtyckiego, jedynie niewielki wiórowiec z krzemienia czekoladowego. Formy te mają ścisłe analogie w zespołach należących do kultur cyklu wstęgowego z Kujaw (Papiernik 2008). Dla czterech prób węgli drzewnych, pobranych z obiektów nie zawierających źródeł ruchomych, otrzymano daty wpisujące się $\mathrm{w}$ chronologię procesów osadniczych kultur ceramiki wstęgowej rytej i ceramiki wstęgowej kłutej w najbliższej okolicy stanowiska. W tym kontekście należy zwrócić uwagę na możliwość penetracji i intensywnego wykorzystywania gospodarczego piaszczystych obszarów Kujaw przez społeczności cyklu wstęgowego. Kwestie te mogą okazać się ważne w dyskusji o relacjach społeczności mezolitycznych i wczesnorolniczych na terenie Niżu Polskiego.

Kolejny i zarazem najliczniej reprezentowany okres zasiedlenia opisywanego miejsca to faza sarnowska kultury pucharów lejkowatych. Przyporządkowano do niej ponad 115 tysięcy fragmentów naczyń i około 15 tysięcy krzemieni, pozyskanych głównie z tzw. warstwy kulturowej. Na obecnym etapie badań należy przyjąć istnienie co najmniej sześciu rozdzielających się koncentracji materiałów, które są pozostałościami stref o intensywnym wykorzystywaniu badanego miejsca i, być może, mają związek z odrębnymi układami siedliskowymi. W ramach tych stref natrafiono na niezbyt liczne obiekty, które można interpretować jako pozostałości domów, studni, składu gliny, palenisk i jam gospodarczych o bliżej nieokreślonej funkcji. Z charakterystycznym dla fazy sarnowskiej materiałem ceramicznym zawierają- 
cym między innymi szczególnie bogaty zbiór talerzy (około 1600 fragmentów tych naczyń) dobrze korespondują liczne wyroby krzemienne wykonane z typowego dla kujawskich inwentarzy „wczesnopucharowych” surowca czekoladowego (Niesiołowska-Śreniowska 1982; 1986). Należy podkreślić jednorodność typologiczną i stylistyczną materiałów z poszczególnych stref stanowiska. Na podstawie 11 oznaczeń radiowęglowych wykonanych metodą AMS dla próbek substancji organicznej przywartych do ścianek naczyń można przyjąć, że osada $\mathrm{z}$ fazy sarnowskiej funkcjonowała w przedziale od 4050 do $3850 \mathrm{BC}$, z największym prawdopodobieństwem zaś w pierwszym stuleciu IV tys. BC (Nowak 2009; Papiernik 2012, s. 216, tab. 1).

Znacznie mniej licznie są pozostałości osadnictwa z młodszych faz kultury pucharów lejkowatych. Wyróżniono kilkanaście fragmentów naczyń o typowej dla fazy wióreckiej ornamentyce, w tym między innymi zdobione regularnym odciskanym słupkiem w połączeniu z tzw. zygzakiem oraz tzw. patykiem owiniętym sznurem, z kolankowatych uchami. Z tą fazą związane są nieliczne wyroby krzemienne wykonane z makrolitycznych wiórów oraz odłupki od gładzonych siekier z krzemienia świeciechowskiego i wołyńskiego. Obecność młodszego osadnictwa dokumentuje również co najmniej sześć oznaczeń ${ }^{14} \mathrm{C}$, na podstawie których należy sądzić, że społeczności kultury pucharów lejkowatych wykorzystywały opisywane miejsce jeszcze w początkach drugiej połowy IV tys. BC.

Następne fazy zasiedlenia terenu związane są ze społecznościami kultury amfor kulistych. W sumie pozyskano ponad 7,5 tysiąca fragmentów naczyń i ponad 200 wyrobów krzemiennych związanych z produkcją odłupków oraz łuszczni (Papiernik 2012). Materiały te odkryto głównie w środkowej i wschodniej części wykopu, gdzie tworzyły trzy koncentracje źródeł, interpretowane jako pozostałości niewielkich osad lub obozowisk. Na obecnym etapie badań nie dysponujemy oznaczeniami wieku bezwzględnego, które można by pewnie połączyć z osadnictwem kultury amfor kulistych. Zatem wstępna interpretacja chronologiczna opisywanych źródeł oparta jest przede wszystkim na stylistyce naczyń ceramicznych, która wskazuje na rozłączność chronologiczną koncentrację materiałów oraz łączenie ich z fazą klasyczną i późną tej kultury (Wiślański 1979; Szmyt 1996).

Należy jeszcze dodać, że na stanowisku odkryto stosunkowo liczne pozostałości osadnictwa o chronologii schyłkowoneolitycznej i z wczesnej epoki brązu oraz kultury łużyckiej. Pozyskano też nieliczne materiały związane z kulturą przeworską, wczesnym średniowieczem i okresem nowożytnym (Papiernik 2012). 


\section{SKEADANKI KRZEMIENNE A ZAGOSPODAROWANIE PRZESTRZENI STANOWISKA W EPOCE KAMIENIA}

\section{Mezolit}

W środkowej epoce kamienia piaszczysty cypel w rejonie płytkiego jeziora Czajno był co najmniej kilkunastokrotnie odwiedzany przez grupy łowców. W wykopie, głównie w jego środkowej, północnej i wschodniej części, zarejestrowano odrębne skupienia z materiałami o cechach mezolitycznych. Koncentracje materiału miały zróżnicowane kształty i rozmiary - od dużych, owalnych, zajmujących około $100-250 \mathrm{~m}^{2}$, po małe koliste, zajmujące kilkanaście metrów kwadratowych. Analiza wytworów krzemiennych z mezolitu za pomocą metody składanek wskazała, że łączą się one w ramach wydzielonych skupień w obrębie wykopu, między którymi nie zarejestrowano jednak połączeń (ryc. 2). Natomiast wyraźnie widoczne jest zróżnicowanie w poszczególnych skupieniach, na przykład w wysuniętym najbardziej na północ, oznaczonym numerem 3 , z powierzchni około $250 \mathrm{~m}^{2}$ pozyskano 531 przedmiotów krzemiennych pochodzących z mezolitu. W dziewięciu składankach, w tym trzech rozbudowanych, złożeniach blokowych, udało się poskładać 75 wytworów, co stanowi 14,1\% złożeń, a po odliczeniu wszystkich okazów nieokreślonych odsetek ten zwiększa się do $20 \%$. Składanki wytworów krzemiennych pozwalają rekonstruować procesy związane z zabiegami przygotowania obłupnia oraz rdzenia, z których co najmniej jeden prawdopodobnie został wyniesiony poza przebadany obszar (ryc. 3). W innych składankach $\mathrm{z}$ tej koncentracji udało się odtworzyć sposób przygotowania narzędzia - rylca, a także sposoby zaprawy oraz eksploatacji kolejnego rdzenia wiórowego.

W innej części wykopu, w skupieniu nr 5, znajdującym się w środkowej części badanego obszaru, udało się połączyć ze sobą największą liczbę wytworów krzemiennych - 135 sztuk w 25 składankach. Udało się odtworzyć głównie zabiegi techniczne związane z etapem zaprawy rdzeni oraz poprawą kąta rdzeniowania, czyli odświeżaniem i odnawianiem pięty rdzenia w trakcie eksploatacji (ryc. 4: 1). Składane były podstawiaki, odnawiaki oraz świeżaki różnych odmian (Wąs 2005). Takie zabiegi stosowano w trakcie seryjnej produkcji półsurowca wiórowego (Inizan i in. 1999) i stanowią one bezpośredni dowód obecności w danym miejscu pracowni wiórów.

Analiza materiałów krzemiennych oraz składanek z poszczególnych skupień z mezolitu wskazuje na doraźność produkcji krzemieniarskiej. Nieliczne, 


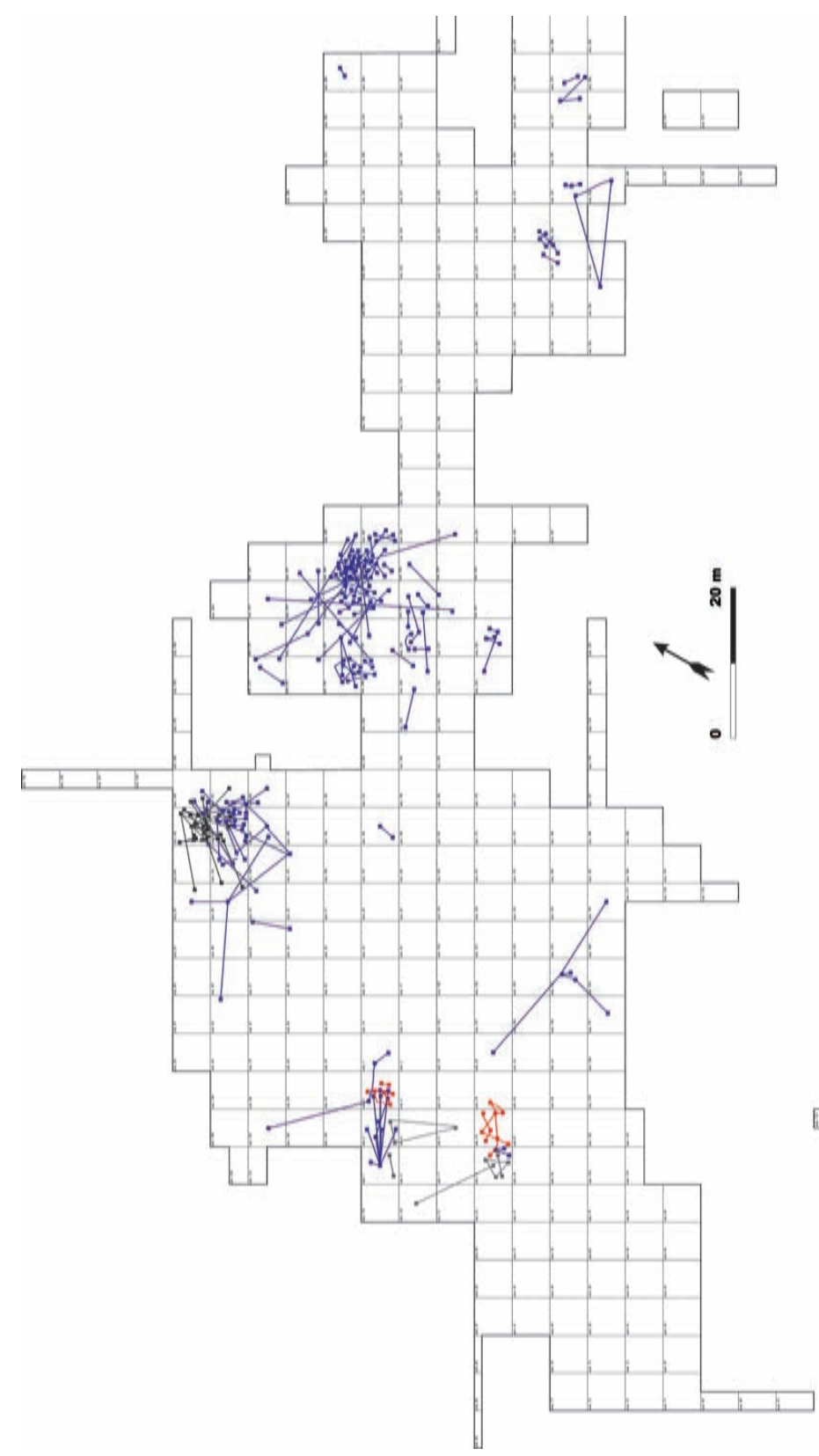

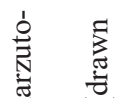

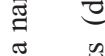

.

素 菖

范

放

量

인.

壱

焉

窟 㤩

함

票 莺

व हे

กิ

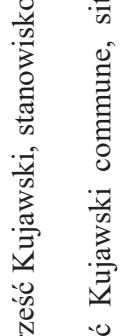

离芯

这

它要

N

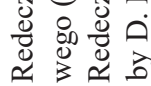

نั 


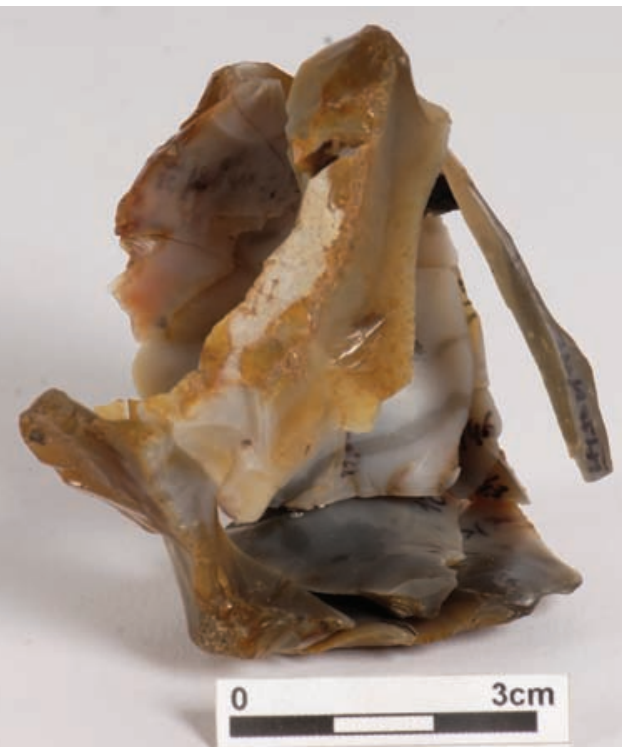

Ryc. 3. Redecz Krukowy, gm. Brześć Kujawski, stanowisko 20. Blokowa składanka odłupków i wiórków. Krzemień narzutowy (fot. W. Pohorecki)

Fig. 3. Redecz Krukowy, Brześć Kujawski commune, site 20. Refitted block of erratic flint chips and flakes (photo W. Pohorecki)

bardziej rozbudowane składanki, łączone ze starszą częścią mezolitu, odzwierciedlają dłuższy, rozbudowany łańcuch operacji (chaines operatoires), jednak bez etapu formowania narzędzi i elementów broni. Przede wszystkim są to jednostkowe połączenia blokowe oraz składanki form technicznych i półsurowca, które wskazują na krótkotrwałość eksploatacji danego miejsca. Dla młodszej części mezolitu udało się zrekonstruować tylko połączenia podwójne lub kilkuelementowe, między innymi narzędzi, nakładki wiórów na rdzenie (ryc. 4: 2) oraz składające się odłupki odtwarzające etap zaprawy boku rdzenia; świadczące o pojedynczych czynnościach.

\section{Faza sarnowska kultury pucharów lejkowatych}

Powierzchnię zajętą przez intensywne osadnictwo fazy sarnowskiej należy szacować w granicach 1 ha. Funkcjonowało tu stabilne, długotrwałe osiedle, poświadczone przez bogactwo materiałów ruchomych i pozostałości różnorodnych obiektów zagłębionych w podłoże. Pozostałości zabudowy wraz z obszarami występowania tzw. warstwy kulturowej tworzą otwarte od strony południowej półkole. Z tymi strukturami koresponduje rozkład przestrzenny materiałów typowych dla fazy sarnowskiej, przede wszyst- 

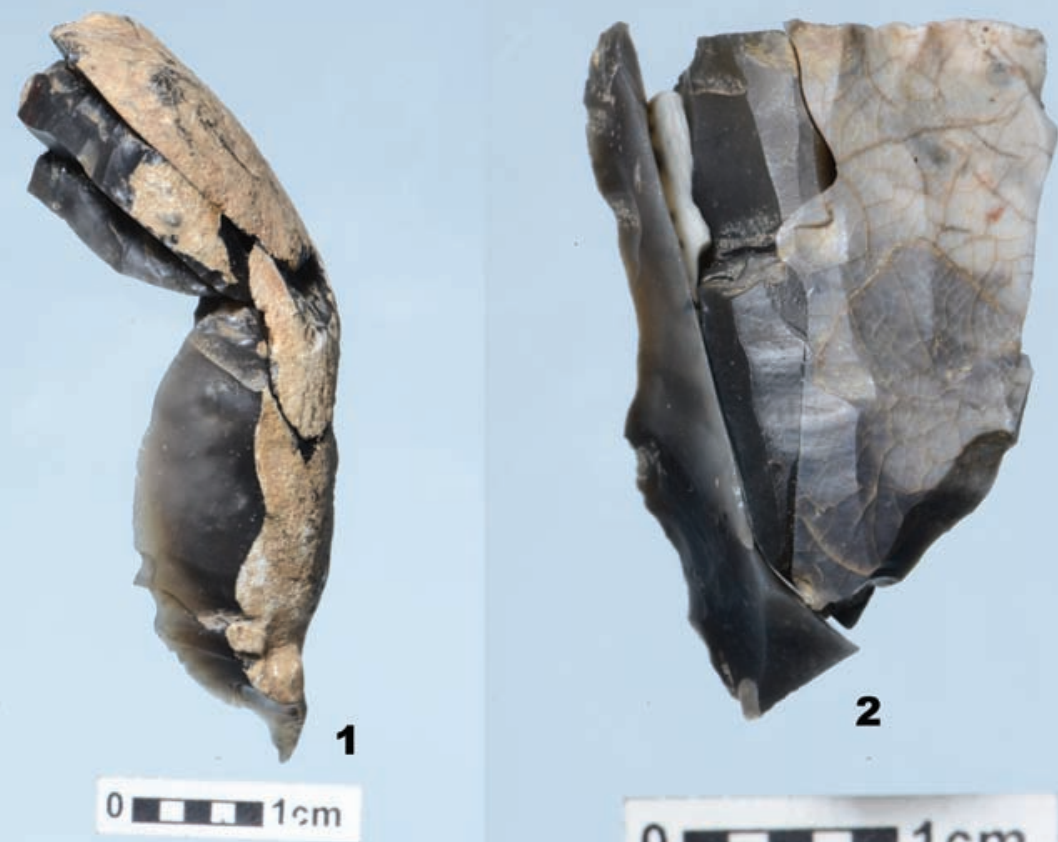

\section{0 प्त $1 \mathrm{sm}$}

Ryc. 4. Redecz Krukowy, gm. Brześć Kujawski, stanowisko 20. Składanki materiałów mezolitu z krzemienia narzutowego: 1 - odnawiaki i odłupki; 2 - składanka rdzenia i wióra (fot. W. Pohorecki)

Fig. 4. Redecz Krukowy, Brześć Kujawski commune, site 20. Refitting of Mesolithic material of erratic flint: 1 - core flakes and flakes, 2 - core and blade (photo W. Pohorecki)

kim ceramicznych z przewodnimi formami w postaci talerzy oraz wyrobów z krzemienia czekoladowego. Wśród tych ostatnich zwracają uwagę liczne regularne formy wiórowe o długości dochodzącej do $12 \mathrm{~cm}$, przy szerokości około $2 \mathrm{~cm}$ i grubości od 4 do $8 \mathrm{~mm}$, odbitych z rdzeni jednopiętowych o starannej eksploatacji. W grupie narzędzi przeważają wióry retuszowane i z retuszem użytkowym, mające wyraźnie spracowane krawędzie lub wyświecenia, mniej liczne są wykonane z wiórów drapacze, półtylczaki i trapezy, sporadycznie zaś występują narzędzia z form odłupkowych. Dużą grupę stanowią okazy łuszczniowe, często niewielkich rozmiarów, których formami pierwotnymi były wyroby pochodzące $z$ procesu rdzeniowania (fragmenty rdzeni, odłupki, wióry, narzędzia). Formą wyjątkową jest rdzeń jednopiętowy, wykonany z krzemienia czekoladowego, niestety, nie udało się do niego dołożyć żadnych zabytków (ryc. 5). 
$\mathrm{Na}$ obecnym etapie badań dysponujemy 183 złożeniami wyrobów z krzemienia czekoladowego (ryc. 6). Nie tworzą one rozbudowanych bloków, dominują połączenia dwu- i trzyelementowe, przy najliczniejszym sześcioelementowym. Składanki zostały wykonane dla różnych grup technologicznych - najliczniej występuje półsurowiec wiórowy, złamany intencjonalnie lub przy padkowo, odtwarzający formę wyjściową (ryc. 7: 4). Zaliczono tu okazy surowe i z retuszem użytkowym. Należy podkreślić, że nie wykonano tzw. nakładek wiórów, tylko w dwóch przypadkach połączono te wyroby z odłupkami. Drugą grupę stanowią składanki narzędzi typologicznych w zdecydowanej większości wykonane z wiórów. Również w tym przypadku odtwarzają one formy wyjściowe, choć wyraźniej widoczne są zabiegi świadomych modyfikacji półsurowca i przeróbek w czasie użytkowania narzędzi (ryc. 7: 1-3). Stosunkowo niewielką grupę stanowią składanki odłupków, wśród których dominują połączenia obejmujące od dwóch do sześciu różnych okazów, pochodzące z redukcji rdzeni odłupkowych dokonywanej tzw. twardym tłukiem (ryc. 8). Niestety, brakuje tu złożeń dokumentujących zabiegi techniczne związane z zaprawą lub naprawami rdzeni wiórowych, w tym świeżeniem lub odnawianiem pięt. Do ostatniej grupy zaliczono formy łuszczniowe, składające się z połączenia łuszcznia i jednego lub kilku odłupków łuszczniowych (ryc. 9). W kilkunastu przypadkach złożenia te tworzą kompletną formę wyjściową, najczęściej jest stosunkowo dużych rozmiarów, odłupek lub fragment amorficznego rdzenia, rzadziej narzędzie odłupkowe lub wiórowe.

Niezależnie od wydzielonej grupy technologicznej znaczną część składanek tworzą połączenia okazów odkrytych w stosunkowo dużej odległości od siebie, rzędu kilkudziesięciu metrów, a nawet od 150 do 200 m (ryc. 6). Wśród nich znajdują się złożenia o wyraźnym obliczu, na przykład pasujące do siebie fragmenty narzędzi wiórowych lub wiórów, także składanki nieokreślonych odłupków czy form łuszczniowych. Warto odnotować, że sieć złożeń wyraźnie nawiązuje do rozkładu materiałów ceramicznych kultury pucharów lejkowatych, w tym również talerzy, a składanki „długodystansowe” łączą poszczególne koncentracje materiałów i rejony występowania tzw. warstwy kulturowej (Papiernik 2012, ryc. 12-15). Obserwacje te są ważnym potwierdzeniem związku krzemieni czekoladowych z osadnictwem „sarnowskim” oraz stanowią istotny argument $\mathrm{w}$ analizie przestrzennej, potwierdzający stabilność osadniczą i znaczne rozmiary osiedla kultury pucharów lejkowatych.

Wśród odkrytych na stanowisku materiałów wspomnianej kultury znalazły się nieliczne fragmenty naczyń ceramicznych i pojedyncze wyroby krzemienne związane z fazą wiórecką. Zapewne większość okazów wykonanych 

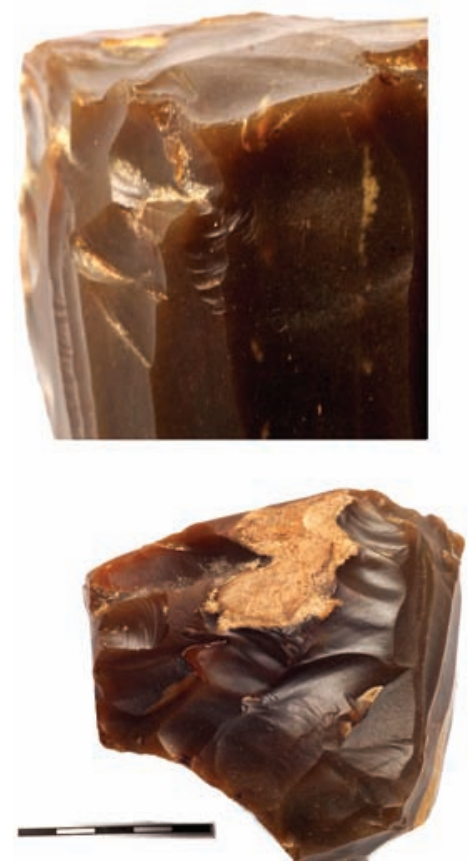
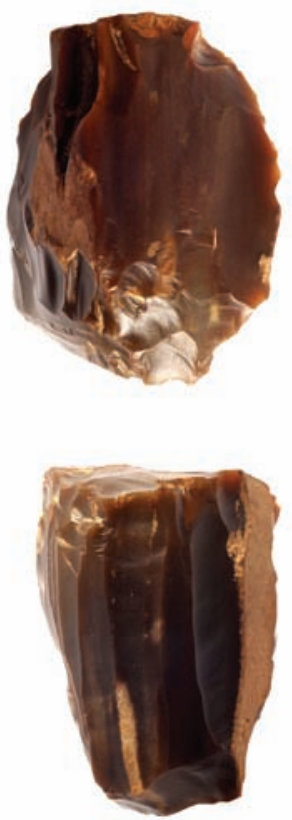

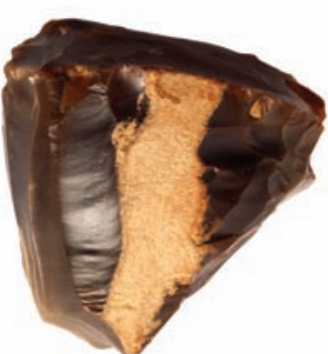

Ryc. 5. Redecz Krukowy, gm. Brześć Kujawski, stanowisko 20. Rdzeń wiórowy jednopiętowy z krzemienia czekoladowego (fot. W. Pohorecki)

Fig. 5. Redecz Krukowy, Brześć Kujawski commune, site 20. Single striking platform blade core of chocolate flint (photo W. Pohorecki)

z surowca świeciechowskiego (10 szt.) należy wiązać właśnie z tą fazą. Cztery z nich, z zachowanymi śladami gładzonych płaszczyzn, udało się ze sobą złożyć (ryc. 10), co świadczy o przerabianiu lub naprawie siekiery. Można zatem odtworzyć sposób użytkowania narzędzia oraz miejsce doraźnej jego modyfikacji w strefie użytkowania zaplecza gospodarczego osady położonej w innym miejscu.

\section{Kultura amfor kulistych}

Składanki wyrobów krzemiennych związanych z kulturą amfor kulistych dostarczyły informacji dotyczących przede wszystkim niewielkiej osady, której pozostałości odsłonięto we wschodniej części wykopu. W tym rejonie, na przestrzeni kilku arów zlokalizowano wyraźną koncentrację fragmentów naczyń ceramicznych, związanych z późną fazą tej kultury. Materiałom tym towarzyszyły stosunkowo liczne krzemienie z miejscowego surowca narzutowego, bałtyckiego i pomorskiego. Kompleksowa procedura złożeń ujawniła 


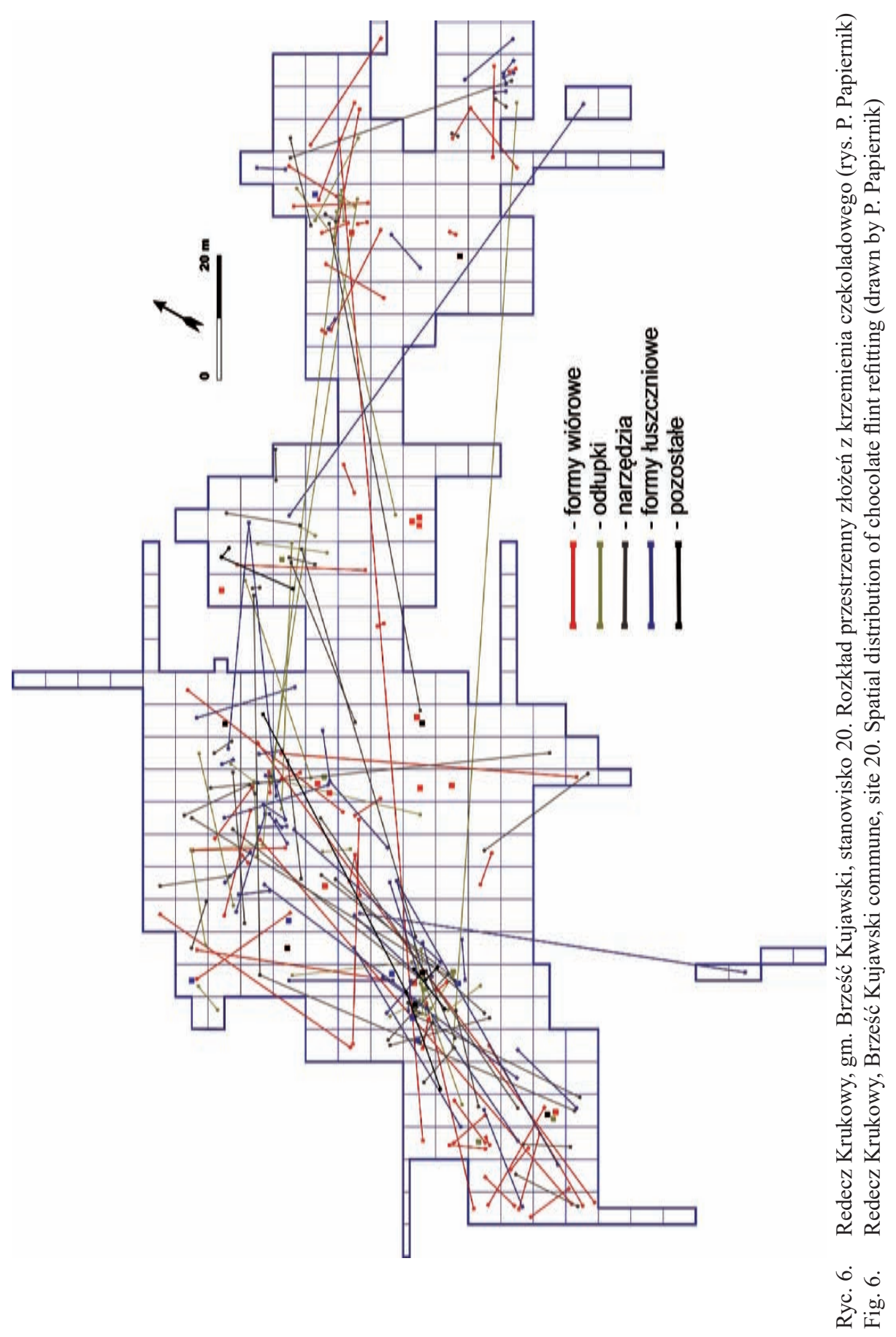



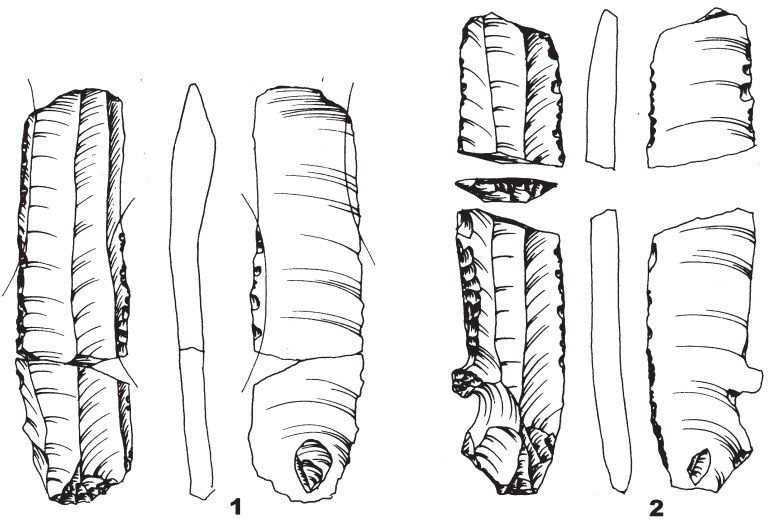

0 $3 \mathrm{~cm}$
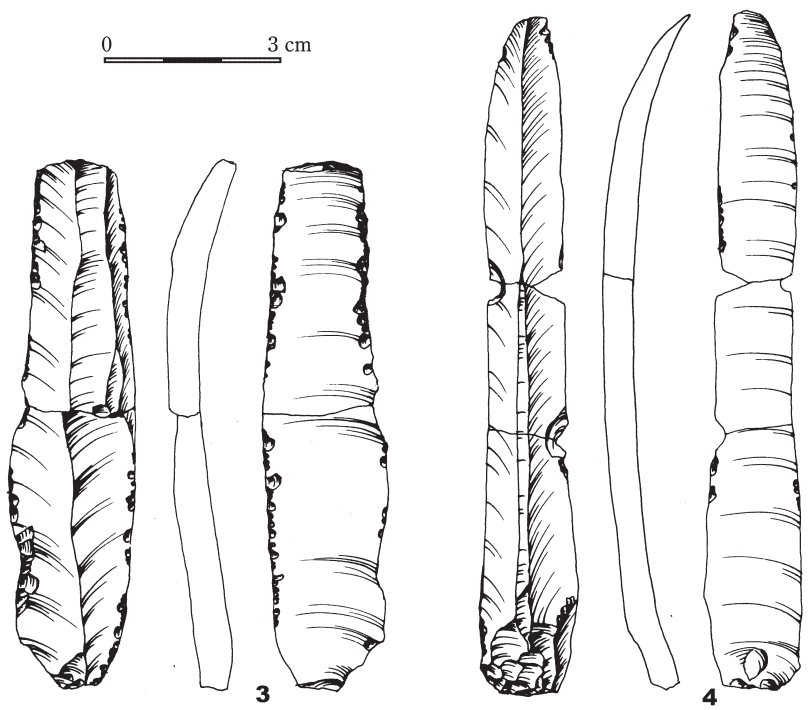

Ryc. 7. Redecz Krukowy, gm. Brześć Kujawski, stanowisko 20. Przykładowe składanki narzędzi (1-3) oraz wióra (4) z fazy Sarnowskiej kultury pucharów lejkowatych. Krzemień „czekoladowy” (rys. E. Górska)

Fig. 7. Redecz Krukowy, Brześć Kujawski commune, site 20. Examples of tool refitting (1-3) and a blade (4) of chocolate flint from Sarnowo phase of Funnel Beaker Culture (drawn by E. Górska)

sieć składanek powielającą rozkład przestrzenny ceramiki kultury amfor kulistych. Ponadto, na podstawie blokowych złożeń można rekonstruować metody obróbki surowca narzutowego, eksploatowanego łuszczniowo i odłupkowo, przy zastosowaniu tzw. twardego tłuka (ryc. 11). Celem produkcji były niewielkie odłupki, zwykłe i łuszczniowe oraz płaskie okruchy, które stanowiły półsurowiec do wyrobu prostych narzędzi retuszowanych i grocików. 


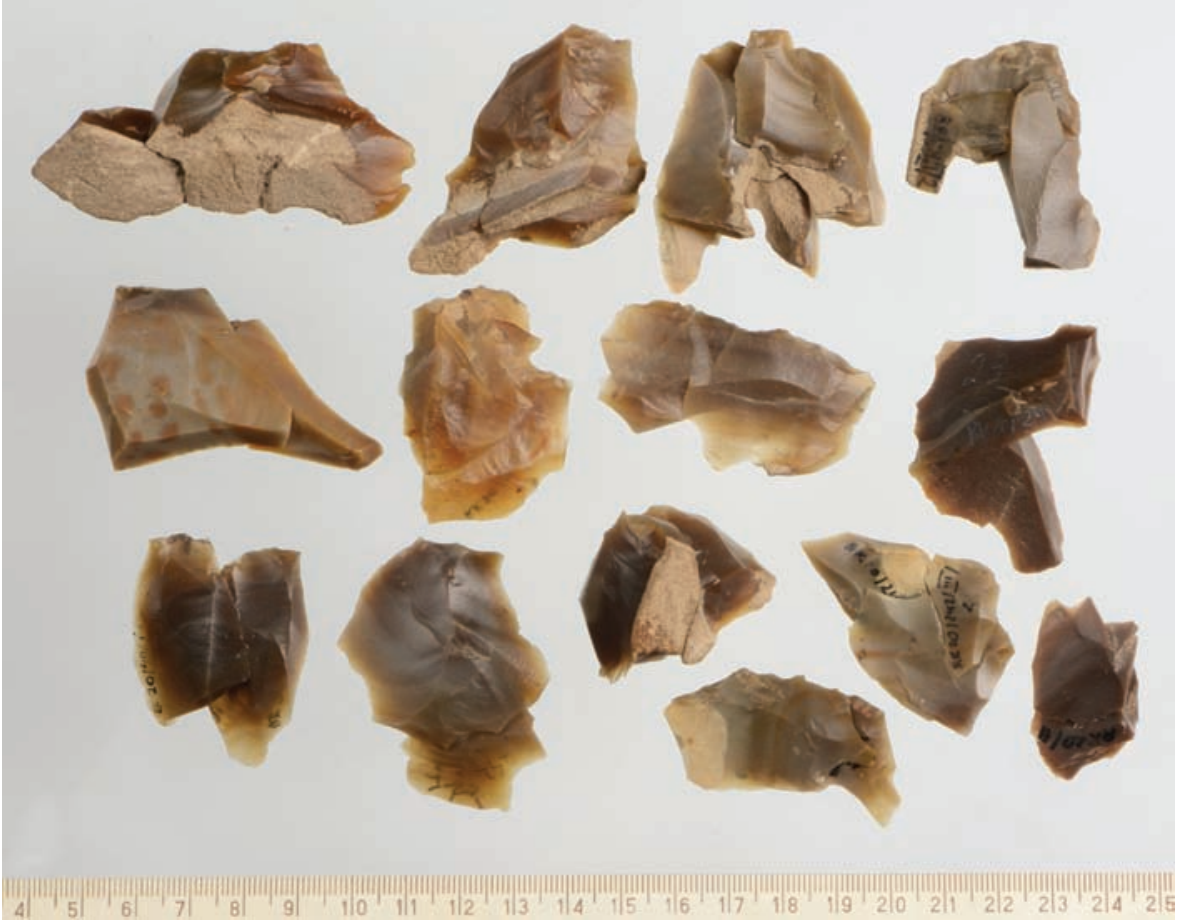

Ryc. 8. Redecz Krukowy, gm. Brześć Kujawski, stanowisko 20. Przykładowe składanki odłupków z fazy Sarnowskiej kultury pucharów lejkowatych. Krzemień „czekoladowy" (fot. W. Pohorecki)

Fig. 8. Redecz Krukowy, Brześć Kujawski commune, site 20. Examples of chocolate flint flake refitting from Sarnovo phase of Funnel Beaker Culture (photo W. Pohorecki)

Z kulturą amfor kulistych prawdopodobnie związana jest także składanka z krzemienia pasiastego, odkryta w środkowej części wykopu na powierzchni 2 arów. W tym przypadku połączono siedem elementów pochodzących $\mathrm{z}$ redukcji większej formy o gładzonych powierzchniach.

\section{PODSUMOWANIE}

Podczas pięciu sezonów badań wykopaliskowych na stanowisku 20 w Redczu Krukowym pozyskano materiały związane przede wszystkim z osadnictwem z młodszej i środkowej epoki kamienia oraz epoki brązu. Dzięki zastosowanej metodzie badań z przesiewaniem wszystkich nawarstwień dla poszczególnych epizodów osadniczych pozyskano wartościowe źródła krzemienne, które poddane zostały procedurze kompleksowego skła- 


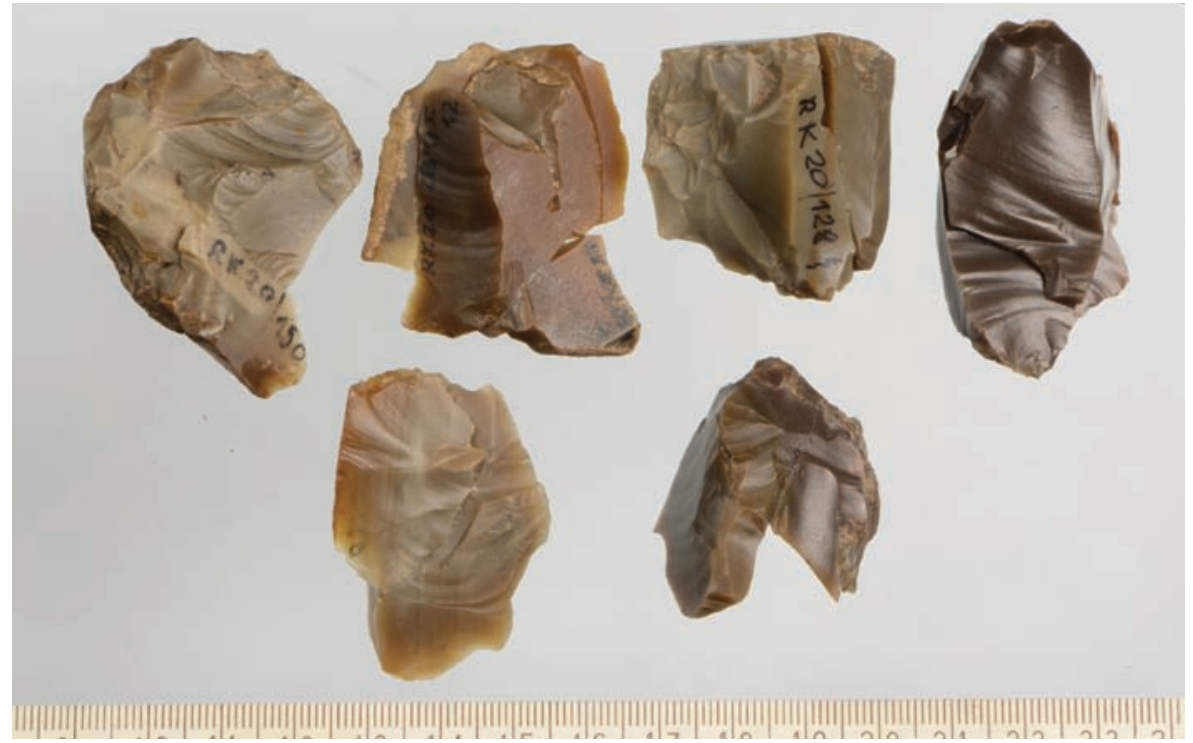

Ryc. 9. Redecz Krukowy, gm. Brześć Kujawski, stanowisko 20. Przykładowe składanki form łuszczniowych fazy sarnowskiej kultury pucharów lejkowatych. Krzemień „czekoladowy” (fot. W. Pohorecki)

Fig. 9. Redecz Krukowy, Brześć Kujawski commune, site 20. Examples of splintered forms of chocolate flint from Sarnowo phase of Funnel Beaker Culture (photo W. Pohorecki)

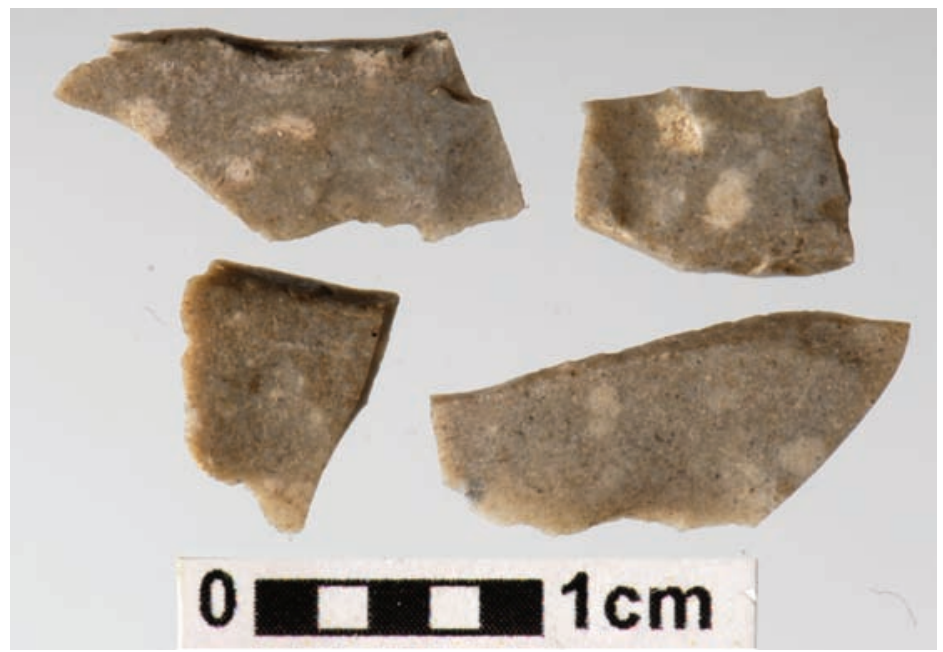

Ryc. 10. Redecz Krukowy, gm. Brześć Kujawski, stanowisko 20. Odłupki z krzemienia świeciechowskiego tworzące składankę prawdopodobnie związaną z kulturą pucharów lejkowatych (fot. W. Pohorecki)

Fig. 10. Redecz Krukowy, Brześć Kujawski commune, site 20. Refitting of flakes of Świeciechów flint presumably attributed to Funnel Beaker Culture (photo W. Pohorecki) 

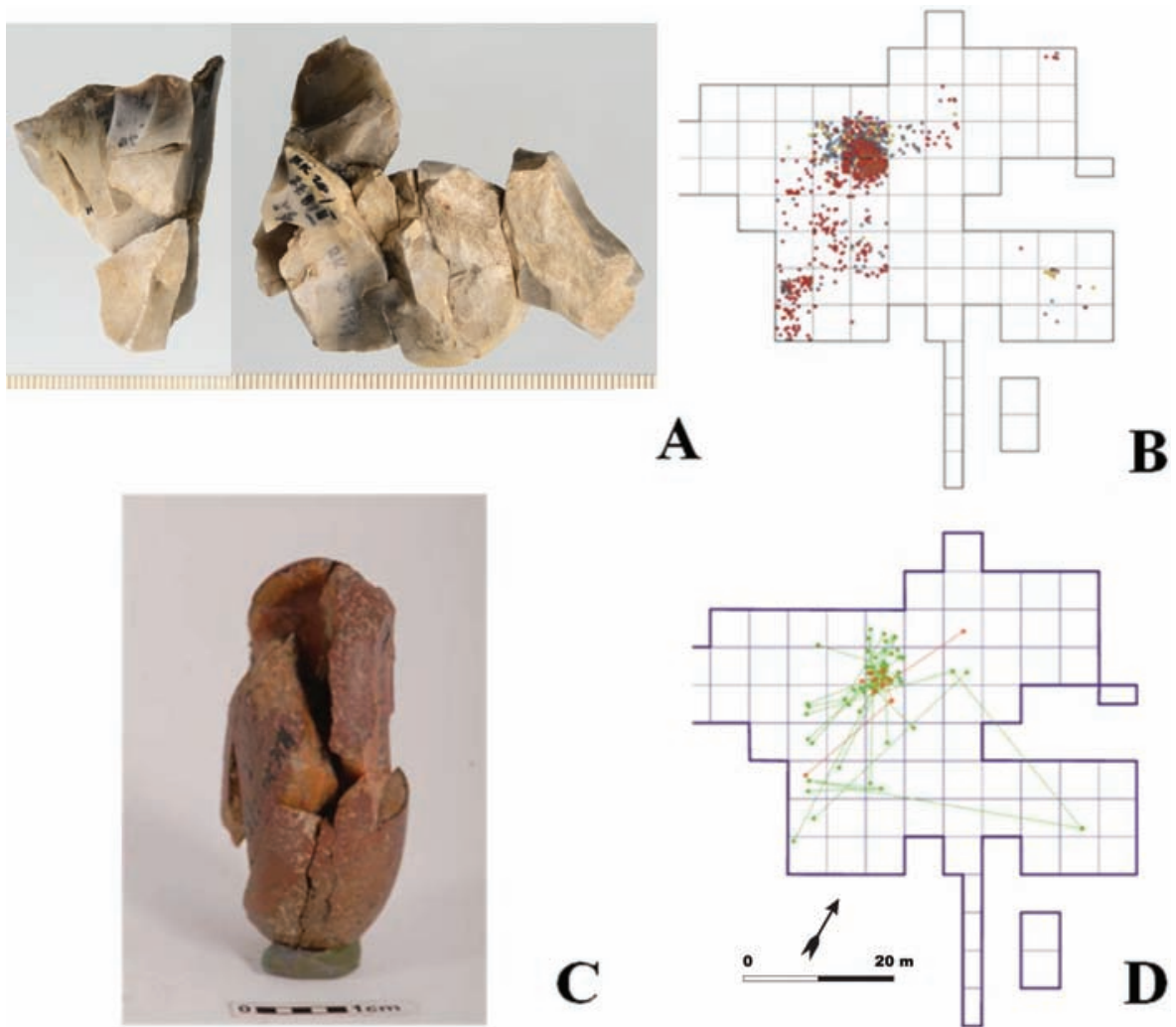

Ryc. 11. Redecz Krukowy, gm. Brześć Kujawski, stanowisko 20. Składanki odłupków z krzemienia narzutowego związanego z kulturą amfor kulistych: A - krzemień bałtycki; B - rozkład ceramiki kultury amfor kulistych; C - składanka bryłki krzemienia narzutowego w odmianie pomorskiej; D - rozkład przestrzenny składanek krzemiennych kultury pucharów lejkowatych (fot. W. Pohorecki, rys. P. Papiernik)

Fig. 11. Redecz Krukowy, Brześć Kujawski commune, site 20. Refitting of erratic flint flakes, attributed to Globular Amphora Culture: A - Baltic flint; B - spatial distribution of Globular Amphora Culture ceramic vessel fragments; C - refitting of Pomeranian erratic flint, D - spatial distribution of refitted elements, consisting of flint material, representing Funnel Beaker Culture (photo W. Pohorecki, drawn by P. Papiernik)

dania. Na obecnym etapie badań szczególnie interesujący jest fakt zróżnicowania technologicznego i przestrzennego składanek przypisanych poszczególnym fazom zasiedlenia badanego miejsca. Kilkanaście niezbyt rozległych, wyodrębnionych, ale bardzo zwartych i potwierdzonych złożeniami koncentracji materiałów krzemiennych ze środkowej epoki kamienia (ryc. 2) stoi w zdecydowanym kontraście do rozbudowanego przestrzennie obrazu składanek i materiałów wykonanych z krzemienia czekoladowego, łączonych 
z fazą sarnowską kultury pucharów lejkowatych (ryc. 6). W przypadku wyrobów tej kultury dominują złożenia dwu- bądź kilkuelementowe (ryc. 7, 8), przy braku połączeń blokowych. Wśród składanek szczególnie liczne są połamane bądź zniszczone w trakcie użytkowania wióry lub narzędzia (ryc. 7). Czytelne są również różnego rodzaju zabiegi związane z eksploatacją bądź niszczeniem rdzeni oraz bryłek krzemienia czekoladowego z zastosowaniem silnego uderzenia bezpośredniego, którego rezultatem były niewielkie odłupki lub łuszcznie i odłupki łuszczniowe (ryc. 8). Składanki ze środkowej epoki kamienia w wielu przypadkach wskazują na znacznie dłuższy i bardziej rozbudowany łańcuch operacji. Szczególnie ważne są tu złożenia zawierające ponad 10 elementów (ryc. 4), tzw. składanki blokowe, które znane są z innych stanowisk na Kujawach (Wąs 1999; 2005). Potwierdzają one obecność pracowni przygotowywania rdzeni lub obłupni (ryc. 3), miejsca eksploatacji wiórów (ryc. 4) oraz produkcji narzędzi do dalszej eksploatacji i użytkowania. Jeszcze inny obraz prezentują składanki materiałów z młodszych faz neolitu, które świadczą o pojedynczych, doraźnych zabiegach, na przykład rozbijaniu bryłek surowca narzutowego (ryc. 9), ostrzeniu siekiery z krzemienia świeciechowskiego (ryc. 10), czy przeróbce narzędzia gładzonego z krzemienia pasiastego. Z materiałami kultury amfor kulistych łączone są także składanki z surowca narzutowego, w tym odmiany pomorskiej, które być może skazują na zastosowanie techniki łuszczniowej do produkcji drobnego półsurowca odłupkowego z przeznaczeniem na grociki (ryc. 11: C).

Powyższe obserwacje wskazują, że w przypadku badań w Redczu Krukowym składanki to wartościowy materiał poznawczy, szczególnie dla zagadnień zróżnicowania technologicznego, powierzchni zasiedlenia oraz zagospodarowania przestrzennego obozowisk mezolitycznych lub osad kultury pucharów lejkowatych i kultury amfor kulistych. Metoda składanek pomogła także w ustalaniu homogeniczności przestrzeni w obrębie przebadanego terenu oraz stanu zachowania opisywanego stanowiska. Poznanie „życia” poszczególnych przedmiotów oraz reguł wykorzystywania surowca krzemiennego jest możliwe dzięki szczególnym walorom poznawczym składanek. Składanki pokazały też indywidualny obraz dla każdego epizodu osadniczego badanego miejsca, co potwierdza występowanie większości materiałów źródłowych in situ. Zgodnie z sugestiami Romualda Schilda stanowiska o złym stanie zachowania dają obraz jednolitego płaszcza krzemiennego i chaotycznie ułożonych linii składanek wytworów krzemiennych (Schild 1975, s. 38). Jak staraliśmy się pokazać w przypadku stanowiska Redecz Krukowy zagospodarowanie przestrzenne jest dobrze udokumentowane wieloaspektowymi analizami, zgodnymi z wynikami metody składanek. 


\section{LITERATURA}

Bagniewski Z.

1996 Mezolit Pojezierza i Równiny Drawskiej, Studia Archeologiczne, t. 18, Wrocław.

Grygiel R.

2004 Neolit i początki epoki brazu w rejonie Brześcia Kujawskiego i Osłonek, t. 1: Wczesny neolit. Kultura ceramiki wstęgowej rytej, Łódź,

2008 Neolit i poczatki epoki brąu w rejonie Brześcia Kujawskiego i Osłonek, t. 2: Środkowy neolit, grupa brzesko-kujawska kultury lendzielskiej, cz. 1-3, Łódź.

Inizan M.-L., Reduron-Ballinger M., Roche H., Tixier J.

1999 Technology and terminology of knapped stone, t. 5, Nantrre.

Kozłowski S. K.

1989 Mesolithic in Poland: a new approach, Warszawa.

Kozłowski J. K., Kozłowski S. K.

1977 Epoka kamienia na ziemiach polskich, Warszawa.

Nalepka D.

2005 Late Glacial and Holocene palaeoecological conditions and changes of vegetation cover under early farming activity in the south Kujawy region (central Poland), Acta Palaeobotanica, Supplementum 6, Kraków.

2008 Late Glacial and Holocen history of vegetation at Osłonki (Kujawy, Central Poland), Folia Quaternaria 78 s. 33-44.

Niesiołowska-Śreniowska E.

1982 Materialy krzemienne z fazy AB kultury pucharów lejkowatych z grobowca 8 w Sarnowie w woj. włocławskim, Prace i Materiały Muzeum Archeologicznego i Etnograficznego w Łodzi, seria archeologiczna, nr 27 , s. $85-135$.

1986 Osada z fazy AB kultury pucharów lejkowatych na stanowisku 1A w Sarnowie, województwo włocławskie, w świetle materiałów krzemiennych i niektóre problemy z nia związane, Prace i Materiały Muzeum Archeologicznego i Etnograficznego w Łodzi, seria archeologiczna, nr 30(1983), s. 201-265.

Nowaczyk B.

2008 Changes in natural environment in the vicinity of Osłonki (Kujawy, Central Poland) in the light of geological and geomorphological investigations, Folia Quaternaria 78, s. 7-32.

Nowak M.

2009 Drugi etap neolityzacji ziem polskich, Kraków. 
Papiernik. P.

2008 Krzemieniarstwo grupy brzesko-kujawskiej kultury lendzielskiej $w$ rejonie Brześcia Kujawskiego i Osłonek, [w:] Neolit i poczatki epoki brązu w rejonie Brześcia Kujawskiego i Osłonek, t. 2, cz. 3: Środkowy neolit. Grupa brzesko-kujawska kultury lendzielskiej, red. R. Grygiel, Łódź, s. 1271-1580.

2012 Sprawozdanie z badań wykopaliskowych na stanowisku 20 w Redczu Krukowym, pow. włocławski, woj. kujawsko-pomorskie, Prace i Materiały Muzeum Archeologicznego i Etnograficznego w Łodzi, seria archeologiczna, nr 45(2010-2012), s. 195-238.

Płaza D. K.

2015 Mezolit na Kujawach, maszynopis rozprawy doktorskiej w Muzeum Archeologicznym i Etnograficznym w Łodzi, Łódź.

Pyzel J.

2010 Historia osadnictwa społeczeństw kultury ceramiki wstęgowej rytej na Kujawach, Gdańsk.

Schild R.

1980 Introduction to dynamic technological differentiation of lithic assamblages in the Upper Palaeolithic: an interpretation attempt, [w:] Unconventional archaeology. New approaches and goals in Polish Archaeology, red. R. Schild, Wrocław, s. 57-85.

Schild R., Marczak M., Królik H.

1975 Późny mezolit. Próba wieloaspektowej analizy otwartych stanowisk piaskowych, Wrocław.

Sørensen M.

2006 Teknologiske traditioner i Maglemosekulturen. En diakron analyse af Maglemosekulturens flckkeindustri, [w:] Tidligt mesolitiske jæegere og samlere i Sydskandinavien, red. B. V. Eriksen, Jysk Arkæologisk Selskabs Skrifter 55, Aarhus, s. 241-275.

Szmyt M.

1996 Społeczności kultury amfor kulistych na Kujawach, Poznań.

Wąs M.

1999 Zespół krzemienny ze stanowiska Dęby 29 w świetle metody składanek, maszynopis pracy magisterskiej w Instytucie Archeologii Uniwersytetu Łódzkiego, Łódź.

2005 Technologia krzemieniarstwa kultury janisławickiej, Łódź.

Wiślański T.

1979 Dalszy rozwój ludów neolitycznych. Plemiona kultury amfor kulistych, [w:] Prahistoria ziem polskich, t. 2: Neolit, red. W. Hensel, T. Wiślański, Wrocław, s. 261-300. 


\title{
SPATIAL ARRANGEMENT IN MESOLITHIC AND NEOLITHIC PERIODS IN THE SITE OF REDECZ KRUKOWY 20, BRZEŚĆ KUJAWSKI COMMUNE, KUJAWSKO-POMORSKIE PROVINCE, IN THE LIGHT REFITTING METHOD
}

\begin{abstract}
Summary
The site 20 in Redecz Krukowy delivered about 25 thousand flint artifacts. Implementing the method of sieving, all the layers revealed precious flint objects, characteristic for particular settlement stages, which were subjected to complex refitting. The material arranged that way demonstrates technical, technological and spatial varieties of collections attributed to certain chronological stages. In Mesolithic inventories, these refitting create small, isolated, but compact concentrations (fig. 2), with particular stress on limp connection (fig. 3), and confirm, among others, presence of a workshop in preparing cores or flakes (fig. 4). Refitting made of chocolate flint and associated with Sarnowo phase of Funnel Beaker Culture, were reported in all the area of the site (fig. 6), with predominance of complex two- or more elements of tools and flakes, broken or damaged during exploitation (fig. 7, 8). Treatments of direct strong hitting in chipping and scaling exploitation are also readable (fig. 8). Another picture is drawn by refitted material originating from younger Neolithic phases; lump connections depicted short-term activity, e.g. casual production of semi-raw flake material of Baltic and Pomeranian flint (fig. 9: A), sharpening axes made of Świeciechów flint (fig. 10) or processing a polished tool of striped flint.
\end{abstract}

Translated by Ewa Józefowicz

Adres do korespondencji:

Piotr Papiernik, Dominik K. Płaza

Muzeum Archeologiczne i Etnograficzne w Lodzi

Plac Wolności 14, 91-415 Łódź

fba@lodz.home.pl,dominik.plaza@maie.lodz.pl 